\title{
Problematizing as a scientific endeavor
}

\author{
Anna McLean Phillips, ${ }^{1, *}$ Jessica Watkins, ${ }^{2, \dagger}$ and David Hammer ${ }^{1,2, \$}$ \\ ${ }^{1}$ Department of Physics and Astronomy, Tufts University, \\ 574 Boston Avenue, Medford, Massachusetts 02155, USA \\ ${ }^{2}$ Department of Education, Tufts University, \\ 12 Upper Campus Road, Medford, Massachusetts 02155, USA \\ (Received 16 January 2017; published 11 August 2017)
}

\begin{abstract}
The work of physics learners at all levels revolves around problems. Physics education research has inspired attention to the forms of these problems, whether conceptual or algorithmic, closed or open response, well or ill structured. Meanwhile, it has been the work of curriculum developers and instructors to develop these problems. Physics education research has supported these efforts with studies of students problem solving and the effects of different kinds of problems on learning. In this article we argue, first, that developing problems is central to the discipline of physics. It involves noticing a gap of understanding, identifying and articulating its precise nature, and motivating a community of its existence and significance. We refer to this activity as problematizing, and we show its importance by drawing from writings in physics and philosophy of science. Second, we argue that students, from elementary age to adults, can problematize as part of their engaging in scientific inquiry. We present four cases, drawing from episodes vetted by a panel of collaborating faculty in science departments as clear instances of students doing science. Although neither we nor the scientists had problematizing in mind when screening cases, we found it across the episodes. We close with implications for instruction, including the value of helping students recognize and manage the situation of being confused but not yet having a clear question, and implications for research, including the need to build problematizing into our models of learning.
\end{abstract}

DOI: 10.1103/PhysRevPhysEducRes.13.020107

\section{INTRODUCTION}

The formulation of a problem is often more essential than its solution, which may be merely a matter of mathematical or experimental skill. To raise new questions, new possibilities, to regard old questions from a new angle, requires creative imagination and marks real advance in science.

-Einstein \& Infeld [1, p. 95]

The notion of a problem is central to physics and to physics education, and there has been extensive attention to students' problem solving both within the physics education research community and in science education more broadly. Along the way, there have been debates over what constitutes a problem, the distinction between problems and exercises, and the merits and authenticity of presenting students with well-structured versus ill-structured problems. Throughout,

\footnotetext{
*Anna.Phillips@tufts.edu

†essica.Watkins@tufts.edu

David.Hammer@tufts.edu
}

Published by the American Physical Society under the terms of the Creative Commons Attribution 4.0 International license. Further distribution of this work must maintain attribution to the author(s) and the published article's title, journal citation, and DOI. educators have worked to help students learn to solve problems in various forms.

Throughout, as well, students and instructors alike have presumed that students solve problems presented by the instructor or textbook. Instructors and textbook authors know the value of "good problems" for learning, and they know the difficulty of composing them-there is a lively market for them among teachers. There is, however, little expectation that the work of constructing a problem is a part of science itself. For most educators, as the recent National Academy of Science's A Framework for K-12 Science Education put it, "Science begins with a question about a phenomenon" (Ref. [1], p. 50).

Our first purpose in this paper is to motivate a different starting point: Science often begins before there is a question, when there is only an uneasy sense that something is missing or amiss. Then the challenge is to identify the source of the unease, to figure out what the gap or inconsistency in our understanding is. We will argue that a problem is itself a scientific achievement, and, therefore, scientific inquiry can begin with the work of identifying, articulating, and motivating the problem that needs solving. We will call that work problematizing. Our second purpose is to show that students are not only capable of problematizing, but that they do it spontaneously in a variety of settings. We will present examples, from particular moments and across a range of contexts, of students' trying to identify, articulate, and motivate a problem. 
In the next section, we discuss how philosophers of science have described problems and provide examples of how physicists have defined and argued for particular problems. We then discuss how current education research and standards support elements of problematizing, although without marking it explicitly. Next, we present several episodes of students' problematizing, comparing them to the examples in professional science. Finally, we argue that educators should recognize problematizing as pervasively evident in student inquiry, and that valuing it as an aspect of science can impact instruction and research.

\section{PROBLEMS AND PROBLEMATIZING IN PROFESSIONAL SCIENCE}

Philosophers of science have described the nature and importance of problems. Henle [2] argued that problems are themselves a dynamic and changing form of knowledge. She used the words "problems" and "gap" interchangeably and described how finding "the shape of the gap" (Ref. [2], p. 173) is a main goal of scientists. In Polanyi's account, "nothing is a problem or discovery in itself; it can only be a problem if it puzzles and worries somebody, and a discovery only if it relieves somebody of a problem" (Ref. [3], p. 122). Bromberger agreed and sharpened the point, describing the state of having a problem ${ }^{1}$ as having a question of a particular sort:

We would consider the question to be sound, that is, to rest on no false presupposition, and to have a correct answer; we would know or believe that we know conditions that the answer must satisfy, but we would not be able to think of any answer that we would not also be forced to rule out. (Ref. [4], p. 69)

That is, a question is only a problem for someone if they expect yet cannot see a solution, given the set of presuppositions.

Combining Henle's account with Polyani's and Bromberger's, we understand two aspects of problematizing. One is the goal to identify and describe the "gap," and the other is the state of puzzlement and unease. Both are evident in the writings of the scientists, as they seek to communicate the nature of the gap as well as to provoke readers to feel it needs to be filled. We turn to examples of those writings now.

Scientists often devote significant portions of their papers to describing their particular view and formulation of a problem. For a famous and highly influential example, Einstein, Podolsky, and Rosen (EPR) [5] argued there was a problem with the theory of quantum mechanics:

\footnotetext{
${ }^{1}$ Bromberger called this state a "p-predicament," where the "p" stands for either puzzled or perplexed.
}

In attempting to judge the success of a physical theory, we may ask ourselves two questions: (1) "Is the theory correct?" and (2) "Is the description given by the theory complete?" It is only in the case in which positive answers may be given to both of these questions, that the concepts of the theory may be said to be satisfactory. The correctness of the theory is judged by the degree of agreement between the conclusions of the theory and human experience. This experience, which alone enables us to make inferences about reality, in physics takes the form of experiment and measurement. It is the second question that we wish to consider here, as applied to quantum mechanics. (Ref. [5], p. 777)

The authors went on to present a thought experiment that showed, in line with Bromberger's account, there was no possibility of a solution given the set of presuppositions, namely, the principles of quantum mechanics along with an ontology regarding "elements of physical reality." Their conclusion in the paper was the existence of a problem: "While we have thus shown that the wave function does not provide a complete description of the physical reality, we left open the question of whether or not such a description exists. We believe, however, that such a theory is possible" (Ref. [5], p. 780).

In another highly influential paper, Guth argued for the "flatness problem." He went to great lengths to convince his reader that there is, indeed, a problem, adding an appendix "For any reader who is not convinced that there is a real problem here" (Ref. [6], p. 348). It concludes with the note:

In the end, I must admit that questions of plausibility are not logically determinable and depend somewhat on intuition. Thus, I am sure that some physicists will remain unconvinced that there is a realflatness problem. I am also sure that many physicists agree with me that the flatness of the universe is a peculiar situation which at some point will admit a physical explanation. (Ref. [6], p. 354)

By arguing that a "peculiar situation" should have an explanation, Guth puts forth the flatness problem and several others as important areas of study. While he did offer a possible solution, in the theory of inflation, he noted it had some "undesirable features," and he was clear that part of his purpose was to "highlight the existence of these problems and encourage others" to work on them (Ref. [6], p. 354).

Finally, for a recent example, we turn to Brustein's formulation of the "black hole information paradox." He motivates his presentation of the problem with the following text in the introduction of his paper:

A possible definition of the information paradox ... is that some tenets of physics have to be abandoned to accommodate the physics of BH's [black holes] ...

The information paradox is a problem of principle, not of practical ability to observe the process of $B H$ 
evaporation with sufficient precision. This process is often compared to the burning of a book. No one doubts that the information in the book can be retrieved (with enough effort) from the fumes and ashes of the fire. On the other hand, everyone accepts that this is practically impossible. So the burning of books was never elevated to the level of a paradox or interpreted as an indication that some fundamental physical principles have to be abandoned. (Ref. [7], p. 255)

Here, Brustein argues that the black hole information problem could be problem of principle in that there is an inconsistency in the "tenets of physics." He thus works to explain the "shape of the gap" as well as to motivate its importance by contrasting it with something similar but nonproblematic, the impracticality of retrieving information from a burned book. As well, he articulates what it means for a theory to be inconsistent, in effect presenting the problem as a form of knowledge, that "some fundamental physical principles have to be abandoned."

These papers are examples of physicists' explanations and arguments to support their claims of problems. Moreover, it is important to recognize that the problems in these cases are the results of extended effort. Einstein had long been uncomfortable with quantum mechanics, but he struggled to formulate a clear demonstration that something was amiss. ${ }^{2}$ Just as it can be difficult to appreciate the work that went into a solution, from the public presentation of its final form, it is difficult to know about the work that went into constructing a problem.

\section{LITERATURE REVIEW IN SCIENCE EDUCATION}

The examples in the previous section motivate our premise that problematizing is a central aspect of scientific inquiry and problems are essential intellectual achievements. In this section we argue that, while there are important beginnings, the science education community has not adequately appreciated the nature of problematizing in science.

\section{A. Characterizations of questions}

Dimension 1 of the Framework for K-12 Science Education [1] posited eight practices of science and engineering, which are now implemented in the Next Generation Science Standards (NGSS) [9]. The first of these is "asking questions":

Science begins with a question about a phenomenon, such as "Why is the sky blue?" or "What causes cancer?," and seeks to develop theories that can provide explanatory answers to such questions. A basic practice of the scientist is formulating empirically

\footnotetext{
${ }^{2}$ Einstein had complained that God is not "playing at dice" as early as 1926, in a letter to Born, nine years before EPR [8].
}

answerable questions about phenomena, establishing what is already known, and determining what questions have yet to be satisfactorily answered. (Ref. [1], p. 50)

Scientific questions are distinguished from other types of questions in that the answers lie in explanations supported by empirical evidence, including evidence gathered by others or through investigation. (Ref. [9], p. 52)

The examples in NGSS focus primarily on what can be investigated empirically or answered by reference texts, such as "ask questions to obtain information about the purpose of weather forecasting to prepare for, and respond to, severe weather" and "ask questions to clarify relationships about the role of DNA and chromosomes in coding the instructions for characteristic traits passed from parents to offspring."

Clearly it is important to pose empirically testable questions. But the descriptions of "asking questions" as a practice in science in the Framework [1] and Standards [9] give only general hints that there is work to do in formulating those questions. Moreover, the descriptions as written make it difficult to consider problems like those in the previous section. EPR and Guth were not posing testable questions; in fact, they knew of no way to investigate their problems empirically. Brustien went so far as to rule out the possibility of an empirical answer to the black hole information paradox.

Research on learning in science has emphasized the importance of wonderment questions that "reflect curiosity, puzzlement, skepticism, or a knowledge-based speculation, in contrast to a groping for basic orienting information" (Ref. [10], p. 188). Chin, Brown, and Bruce divided wonderment questions into five categories, including "comprehension questions which typically sought an explanation of something not understood" and "anomaly detection questions where the student expressed skepticism or detected some discrepant information or cognitive conflict and sought to address this anomalous data" (Ref. [11], p. 532). Similarly, Watts, Gould, and Alsop describe elaboration questions as "indicative of trying to reconcile competing ideas, the demands of a new theory against the call of experience" (Ref. [12], p. 61).

From there, this work has considered how wonderment questions are productive for inquiry: for their role in constructing explanations and knowledge [11,13,14], encouraging engagement and argumentation [15,16], designing experiments and investigations [17], and as evidence of students' existing knowledge [13,14,18].

This work is helpful: The recognition and characterization of comprehension and anomaly detection questions make room for problems like those we described in the previous section as part of and important to science. Yet it generally falls short of valuing questions or problems as achievements in and of themselves and of studying how those questions come to be. If the problems are valuable in science, then so is the intellectual activity to produce them. In other words, scientific inquiry involves activities in which identifying, articulating, and motivating problems are the epistemic aims 
[19]. Our focus here is to recognize and attend to problematizing as part of students' engagement in science.

\section{B. Attention to students' formulating questions}

There has been attention in science education research to the activity of formulating questions, but again mostly for those that are "empirically answerable" (Ref. [1], p. 50). Chin and Kayalvizhi, for example, were concerned with helping students "[i]dentify problems and pose questions that are feasible for investigations" (Ref. [17], p. 269).

Some studies have considered how to support asking questions more generally. Herrenkohl and Guerra described classes constructing a "question chart designed to help students answer the following question: 'What questions could we ask when it is our job to check predictions and theories [or summaries of results or the relation among predictions, theories, and results]?"' (Ref. [20], pp. 445, 446]). Lee and Choo [21] examined how students may formulate well-structured problems [22], in which there is a clear path to a solution, within ill-structured problem settings.

These studies attend to the intellectual work of students' constructing questions. We are suggesting the need for significantly more attention, expanding beyond the construction of well-structured, testable questions. Even formulating an ill-structured problem can take work, and this work is important to recognize as part of doing science. All of the problems from physics we described above, by Guth, EPR, and Brustien, were ill structured in the sense of Refs. [21,22]. None, as we have noted, were "empirically answerable" in the authors' formulation. They were, nonetheless, powerful intellectual achievements, and of seminal value to the scientific community.

The framework of Engle and Conant for fostering students' "productive disciplinary engagement" includes problematizing as a guiding principle for instruction and the design of learning environments [23]. In Ref. [24], Engle developed the notion further, building on Zaslavsky's ideas in mathematics education, to define problematizing as "any individual or collective action that encourages disciplinary uncertainties" [25]. Engle's work is the clearest we have found to describe problematizing as a part of students' engagement in science.

\section{Need for research on student problematizing}

To this point, we have presented examples of problems from professional physics as forms of knowledge in their own right that can be challenging to produce and have seminal impact on the field. These examples motivate our premise: The work of identifying, articulating, and motivating problems, which we call "problematizing," is of central importance to the practices of science. We have also discussed how science education has only begun to consider problematizing as part of doing science.

To be clear, we do not argue that students' engagement in science must involve problematizing — certainly students can engage in doing science through solving problems presented by the teacher or curriculum. Rather, we argue that it is a part of doing science the community has mostly overlooked. In the following section, we provide examples of students' problematizing to show that it is part of what they do, without explicit attention in instruction, as evidence of their nascent abilities.

\section{METHODOLOGY}

Our work on problematizing arose out of larger project in Ref. [26]. The purpose of that project, as the title suggests, is to understand what contributes to students' engagement in doing science.

In that project, our initial task was to identify episodes to study. We did that in two steps, drawing on existing data from previous projects and collecting new data in college science courses. The first step was to select candidate episodes in the data, as brief as a few minutes to several days of activity, that we saw as possibilities. These all involved substantial student talk and sense making about phenomena, captured on video (with one or two cameras); some included copies of students' written work.

We then presented the candidates to a panel of collaborating scientists, faculty from departments of biology, chemistry, and physics. Their job was to vet the candidates for clear examples; we only proceeded with those for which there was an easy consensus that the data showed students doing science. In this way, we aimed to avoid nuanced debate over what constitutes science, and neither we nor the panel imposed a single set of criteria. There was, in particular, no prior discussion about problematizing as part of identifying cases. The panel identified nine cases, ranging in length from five minutes to nearly half an hour, as clear examples.

Table I shows the nine cases. The first four are from the project Responsive Teaching in Science [27]. The fifth is from an inquiry course for preservice teachers [28-30], and the remaining four are new data from college courses. Of those four, three took place in courses taught in lecture halls, including approximately 75 students. The remaining one took place in a recitation section.

Having selected clear examples of students doing science, we distributed them to the researchers on the team for analysis. The goal was to understand, in each case, the moment-to-moment dynamics of the students' thinking and behavior. As much as possible, we treated each case on its own, drawing on methods from video research in the learning sciences [32] to identify and bound the data for study, discourse analysis [33] for markers of how students framed what was taking place, and interaction analysis [34] to make inferences about the substance and meaning of individual contributions as well as the nature of the concerted activity [35] of the group. A more detailed description of our analytical approach can be found in Ref. [36].

Once the individual case studies were complete, we looked for patterns across them. One pattern, which we discuss elsewhere [36], was that in every case some 
TABLE I. Our nine case studies. Problematizing was prominent in the dynamics in the cases in bold font. Starred cases are presented here and in the Supplemental Material [31].

\begin{tabular}{|c|c|c|c|c|}
\hline Case & Context & Class size & Topic & Description \\
\hline Isaac's wheels & $\begin{array}{l}\text { Third grade classroom, } \\
\text { public school }\end{array}$ & $\sim 25$ & Motion and energy & $\begin{array}{l}\text { Students discuss a peer's model of how a wheel } \\
\text { rolls without slipping. }\end{array}$ \\
\hline Freezing water* & $\begin{array}{l}\text { Fifth grade classroom, } \\
\text { public school }\end{array}$ & $\sim 30$ & Phases of matter & $\begin{array}{l}\text { Students discuss how a water bottle can expand } \\
\text { when it freezes. }\end{array}$ \\
\hline Jordan's clouds & $\begin{array}{l}\text { Fifth grade classroom, } \\
\text { public school }\end{array}$ & $\sim 20$ & Motion and energy & $\begin{array}{l}\text { Students discuss a peer's model of how a wheel } \\
\text { rolls without slipping. }\end{array}$ \\
\hline Rubber band & $\begin{array}{l}\text { Fifth grade classroom, } \\
\text { public school }\end{array}$ & $\sim 25$ & The water cycle & $\begin{array}{l}\text { Students discuss various explanations for how } \\
\text { clouds suddenly release rain. }\end{array}$ \\
\hline The fuzzy edge* & $\begin{array}{l}\text { Science inquiry class for } \\
\text { preservice teachers }\end{array}$ & $\sim 25$ & Light & $\begin{array}{l}\text { Students investigate why light traveling through a } \\
\text { paper tube has a "fuzzy edge." }\end{array}$ \\
\hline Ball on a string & $\begin{array}{l}\text { College introductory } \\
\text { physics lecture }\end{array}$ & $\sim 75$ & Forces and motion & $\begin{array}{l}\text { Students discuss how the net force on a ball on a } \\
\text { string must act to provide the correct } \\
\text { acceleration. }\end{array}$ \\
\hline $\begin{array}{l}\text { Block and } \\
\text { cylinder* }\end{array}$ & $\begin{array}{l}\text { College introductory } \\
\text { physics lecture }\end{array}$ & $\sim 75$ & Rotational motion & $\begin{array}{l}\text { Students argue over the answer to a homework } \\
\text { problem about pulling on a ball and cylinder. }\end{array}$ \\
\hline $\begin{array}{l}\text { The work by } \\
\text { an escalator* }\end{array}$ & $\begin{array}{l}\text { College introductory } \\
\text { physics recitation }\end{array}$ & $\sim 20$ & Force and energy & $\begin{array}{l}\text { A student comes up with a new question based on a } \\
\text { homework problem, and she and her peers work } \\
\text { to answer the new question. }\end{array}$ \\
\hline Van de Graaff & $\begin{array}{l}\text { College introductory } \\
\text { physics lecture }\end{array}$ & $\sim 80$ & Electrostatics & $\begin{array}{l}\text { Students discuss the odd behavior of mylar } \\
\text { streamers attached to a Van de Graaff generator. }\end{array}$ \\
\hline
\end{tabular}

participant positioned themselves as not understanding. This article concerns a related pattern: In all nine cases, students did work in one way or another to articulate and motivate some particular lack of understanding. In seven of those nine, this work was a main part of the dynamic, taking place over four or more minutes and involving four or more participants. It was in this way that we identified problematizing as something to study.

\section{PROBLEMS AND PROBLEMATIZING IN STUDENT INQUIRY}

Space constraints limit us to presenting excerpts from two case studies and summaries of two more in this article. We have chosen "freezing water" and "block and cylinder," from the list in Table I, based on feedback for what journal readers would most appreciate. We present two additional cases, "the fuzzy edge" and "the work by an escalator," in the Supplemental Material [31]. Our claim is that these instances, selected as exemplars of students' "doing science," involve problematizing. This motivates us to suggest that problematizing is a common aspect of student inquiry that educators could recognize and support.

\section{A. Freezing water}

This case is from a unit on the water cycle in a 5th grade science class [37]. Students had earlier read and discussed the model in their textbook of how molecules move faster and spread apart when heated.
At the start of the episode, a student, Ben, suggests that molecules get "packed together" when water freezes. A few turns later, a student, Jared, uses this same phrase to point out an inconsistency. ${ }^{3}$

Jared: Have you-if you've noticed, like, if you put the water bottle in the freezer or something, how it just, gets expa:::nding [Figs. 1(a) and 1(b)], like, 'cause you said that they freeze and they get all packed together so wouldn't packed together [Fig. 1(c)] mean smaller?

DC: No.

Jared: In any occasion-

DC: Packing together means tha $=$

Jared: 'cause you know how you should- you could drink a little bit or pour a little bit out because if you just put it in, and freeze it: the pop could get all off and the water bottle could get damaged, =

DC: Well, Jared,

Jared: $=$ because it expands

DC: Well, connecting everything will make it bigger. Say, we were a class and we just huddle in like a giant ball of circle, and we would be- we would be a giant

Jared: No, we're giant right n-, if we all went- like huddled together then we would be smaller.

\footnotetext{
${ }^{3}$ We use the following transcription conventions: :: means extended vowel;-means interrupted speech; = means latched speech; [] denotes overlapping speech; all capitalized text indicates strong emphasis on a syllable; and all italicized text indicates emphasis on a phrase. Statements in parenthesis note gestures, actions, or events that take place.
} 


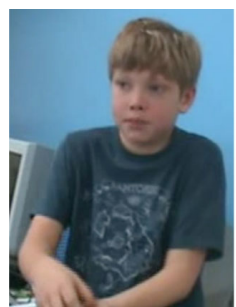

(a)

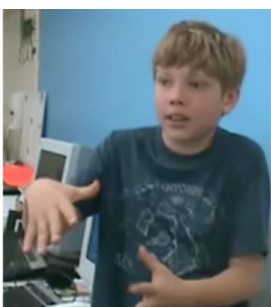

(b)

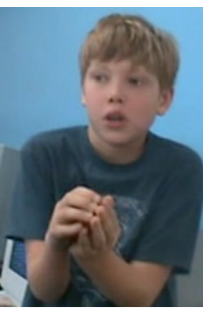

(c)
FIG. 1. Jared gestures as he says "expanded" (a),(b) and "packed together" (c).

DC: No

Ben: BUT yeah, we wouldn't-

Jared: Like if there's two guys and they're standing right here, [but if they weren't together then]

Ben: [Like if we had kids all around the classroom,] and, say, each kid represented a water molecule, and and it's hot water 'cause we're all around the classroom, if we were all packed together like on the rug over there-

DC: We'd be big

Ben: (turns towards DC) We would be big, but we wouldn't have to make the classroom expand-

DC: We would just be expanding ourselves. pause

DC: Well, in the water bot-

Teacher: so how does that happen Jared-

Jared: If we're spread out, wouldn't that mean spread OUT and not packed together?

DC: Well Jared,

Jared: A pool of water is expanded more than an ice cube, isn't it?

DC: Well Jared, it expands because it's forming into ice, and then the ice expands. The cup, which, well the glass bottle-which makes it crack open

Jared: Yeah, that's what I'm saying

Jared wants to call attention to an inconsistency between their model and a familiar phenomenon: Water expands when it freezes. He reminds students that they do not fill a water bottle completely before putting it in the freezer. At the same time, their model says that water should get smaller as molecules "get all packed together" in freezing.

However, DC is not convinced there is a problem. He argues that packing together means expanding, with an analogy to students in the classroom: Huddled together, "we'd be big." Jared compares that huddle to their larger size when they are spread out in the classroom. In these negotiations, the students use subtly different language: DC refers to the students (and molecules) being a giant, but Jared refers to them being giant. Ben adds a new element to consider, noting that the size of the ice cube (or the group of huddled students) can be large while still not requiring the container (or the classroom) to expand.

Jared continues to argue that "spread out" would mean larger. He contends "a pool of water is expanded more than an ice cube," which seems to contradict his earlier argument that water expands as it freezes. At that point it is DC who claims that "ice expands," resulting in confusion about the nature of their disagreement.

The episode continues with other students joining in the conversation, trying to understand the arguments they have heard. Approximately five minutes later, the teacher summarizes the consensus that water does expand when it freezes, and she points out the apparent contradiction: "If we all squished ourselves together, I don't think we all of a sudden are bigger!" Jared then explains what he thinks the model would predict:

Jared: Well, here, like, here's what I'm saying.

Teacher: All right.

Jared: Here's what I'm saying. If it's like, if it's like, so let's say there's all these molecules between DC, me, Ms. Filner, and Inger (pointing to the different people) We're spread apart but we're all this big piece of water, but if we pack up in an ice cube, then we're smaller than what we are in like in a big thing, [so-

DC: [Well], Jared, [I actually had-

Jack: [But then how does it exPAND [like what you're saying]

Teacher: [But you guys said that] the ice cube actually pops up and it gets bigger

Jared: Yeah, exactly, that's the point.

DC: But Ms. Filner -

Jack: But how does it expaaaand?

Drawing again on the analogy of students as water molecules, Jared argues that the class's model predicts that an ice cube would be smaller than "the big piece of water" before it freezes. Jack asks how the ice actually expands, and the teacher brings back the students' observation that ice gets bigger as it freezes, using the word "but" to highlight that what Jared has said is inconsistent with the observation. Immediately, Jared says "Yeah, exactly, that's the point," first looking at Jack and then at the teacher.

The point for Jared is the problem: the theory they have for how molecules respond to temperature is inconsistent with observations that water expands when it freezes. Our claim is that the work the students were doing in this episode was problematizing, that is the work of identifying and motivating a particular lack of understanding.

At the start, Jared suggested there was a problem, but it was not immediately clear to everyone. Articulating the problem and convincing others that the problem existed took time and work. To agree on what the model predicted, they drew on different verbal and gestural representations to clarify what it means to pack together and to spread apart. They drew on their experiences with freezing water, drawing on different observations as evidence that the volume expands. They also had to work to understand and make connections to each other's ideas. This is meaningful scientific work, not in service of motivating a model, but in motivating a problem. 
Note, too, the progress in their articulation of the problem. Jared's first concern was to point out the inconsistency between the model of water molecules packing together and the observation of expansion, when water freezes. Jack's articulation is a subtle but important shift toward asking for a mechanism: How does the water expand, when the molecules pack together?

We stop our analysis there. In class, the students continued to work on the problem, and developed an explanation by analogy to crumpling a piece of paper: The molecules connect and push away from each other, leaving space between them [38].

\section{B. Block and cylinder}

This case is from a calculus-based introductory mechanics course, with approximately 75 students, mostly majors in engineering. The course had similar structure to those described in Ref. [39], with lecture, labs, homework assignments, and discussion sections designed to promote productive epistemologies. The third author, David, was the professor.

The episode we examine took place during a lecture near the end of the semester [40]. It centers on a homework question based off of an exercise described in Ref. [41]. David introduced the topic saying, "I have one more from last night that I want to go through very briefly," polled the students for their answers, and invited their arguments. Despite his intention for brevity, the discussion lasted about 30 minutes. We focus on two moments of problematizing, one near the beginning of the discussion and one near the end.

On a homework assignment students were presented with the image in Fig. 2 and asked to answer the questions below.

A block and a cylinder, each of mass $\mathrm{M}$, are on a level, frictionless surface. There's a string tied to the center of the front of the block, and another string wound many times around the cylinder. Each string exerts the same force. The cylinder has radius $R$ and height $2 \mathrm{R}$; the block has sides $2 \mathrm{R}$.

(a) If they both start from rest, which one gets to the finish line first?

(b) Find the angular acceleration of the cylinder.

In lecture immediately after the assignment was turned in, David displayed that image again, with the following text as a clicker question

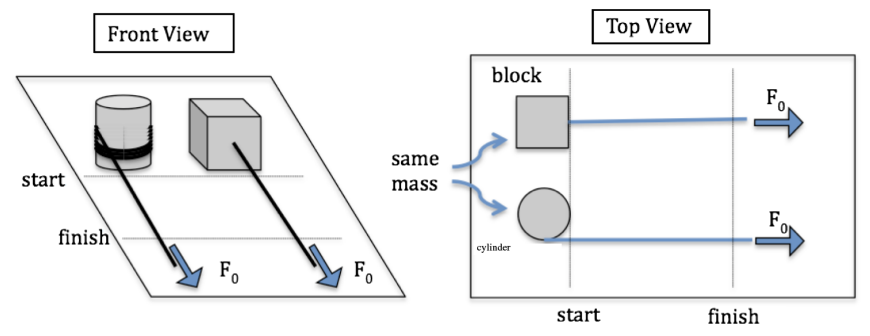

FIG. 2. The figure adapted from Ref. [41].
Which wins?

(A) The cylinder

(B) The block

(C) It's a tie

Eighty-nine percent of the students chose B, and David asked them to explain "Why does the block win?" Two students replied with their answers from homework: For the cylinder, some energy goes into rotation; for the block, all the energy goes into translation. Maayan said it is the same reasoning as in an earlier problem, comparing a block sliding to a ball rolling down a ramp.

Michael, a student who spoke often in lectures, disagreed.

Michael: (emphatically) No it isn't.

David: Uh oh.

(murmuring)

Michael: It is not the same as the ball rolling down the ramp. The ball rolling down the ramp involves friction, static friction. One of the premises of this problem was there is no friction. Which, which gave us quite a lot of problems when we were discussing it in our recitation. So whatever you believe happens, it fundamentally isn't the same. Where I ended up is that I looked at the forces on the center of mass and found that there was only one and it was F. And from that it would have to be that the acceleration was $\mathrm{F}$ and it would reach the end at the same. But I wasn't really happy with it.

David: So you say, you say it's the same because they have the same total force acting on them. But you're not really happy with that.

Michael: I'm not happy with it.

David: All right, Um, maybe I'll, in a minute, I might ask you to express your unhappiness, but there are other folks.

Part of Michael's contribution is similar to the first two students', in that he explains a line of reasoning, confident it is correct: This question is different from the ramp question. (He had considered a similar energy conservation argument on his problem set.)

In other respects, Michael's contribution is to problematize. His saying this "gave us quite a lot of problems" is the first signal there is something still to figure out. He then introduces his reasoning as "where I ended up," the block and cylinder must tie because they experience the same force, and says he "wasn't really happy with it." Thus, Michael conveys uncertainty [36] and ongoing puzzlement. His comment invites the question of what has him unhappy; in other words, Michael's contribution is a bid to articulate a gap or inconsistency.

One result, apparently, is that many students now have things to say. David defers asking Michael to speak further in order to call on others. Another consequence, perhaps, is students shifting to speaking in the first person about their own understanding, constructing new arguments-that is, not simply reporting their answers from the homeworkand responding to each other. In this way, the data suggest, Michael contributed to his peers' taking up uncertainty and 
working to articulate a problem: Energy arguments appear to support the block winning, yet arguments based on forces support the conclusion that block and cylinder tie.

Over the next 20 minutes, students introduce a variety of arguments, including that the block must win because it will take longer to pull all of the rope off the cylinder; that the relevant distance is the amount of rope and therefore more work is done on the cylinder, allowing them to tie; and that the force on the cylinder is less effective at accelerating it because it is not applied at the center of mass. One student, Connor, offers additional evidence: he had experimented using headphone cord, one side tied around a can to make it like the block and the other side wrapped around a similar can like the cylinder. Michael states that he, too, conducted a similar experiment.

When eventually David gives the answer, that the block and cylinder tie, there is an audible reaction of surprise, with at least one student shouting "No!" In his explanation, David highlights Michael's original argument: that the forces on the center of mass are the same and therefore the equal-massed objects tie. David makes a bid to move on, but students, particularly Connor, press to continue.

David: So, all right, let's, I wanna, I wanna go on, there are things about this that might still bother you. Connor?

Connor: If this was done with friction would the answer be block?

David: If the-if this were done and there were friction on the surface would the answer, would the answer be the block. Um

[Pat, sitting near David in the front row, says something inaudible in the recording.]

I, I have to believe Pat, she says no, it would be the same force of friction. They both have kinetic friction.

Maayan: $\mathrm{Cuz}$ the, cuz the cylinder is spinning a lot more, it's creating a lot more frictional [inaudible].

Michael: But the frictional force is directly-

David: -But the size of the force, the size of kinetic friction force should be equal in both cases so it should be the same in both cases. Yeah?

Chris: But the surface area on the cylinder that's in contact with the surface is less.

This shows another moment of problematizing, evident this time in a student constructing a new version of the problem: Which wins if there is friction?

Connor had spoken of his result earlier, that the block won, and hearing David endorse the answer of a tie apparently had him working to reconcile the discrepancy. That is, Connor saw the problem of how the formal answer could be a tie when his experiment showed the block winning. He evidently refined that problem to form another, effectively to consider the more specific conjecture that the difference is friction.

In this section, students speak rapidly, interrupting David and each other. Their quick questions and contributions indicate that they are still interested in pursing the question, and it appears as though they are attempting to motivate the instructor to further pursue the problem that they see.

It is a new question for David, who pauses to consider it. As he does, student Pat says she thinks the friction would have to be the same, for the block and the cylinder, reasoning David repeats to the class and endorses. The students considered this reasoning, until shortly later David offered a different reconciliation of Connor's result, that the forces acting on the two objects were not the same.

These two instances of problematizing from the block and cylinder episode show different ways it can appear in student discourse. In the first, Michael expressed an unease that he had not yet captured in words; in the second, Connor constructs a new version of a problem, as part of trying to understand the original.

We now describe two more cases briefly; more complete analyses can be found in the Supplemental Material [31].

\section{Escalator}

This episode took place earlier in the semester during a discussion ("recitation") section of the same course as block and c. As with that case, students had completed a homework question that sparked significant discussion: How much work does an escalator do on you if you walk up instead of standing still? In lecture, David gave the answer that the escalator does less work on you if you walk up.

Several students entered the discussion section still puzzled. Working to articulate her unease, Pat posed a new, related question: How much work does the escalator do on you if you jump up and down on the same step? The question was a productive achievement, not only for the students in the discussion but also for the course going forward, when it was posed to students in subsequent years.

\section{Fuzzy edge of light}

This episode took place in a science inquiry course for preservice teachers at a public regional university [28-30]. The students were experimenting with wrapping flashlights in paper tubes to see if they could create a visible beam of light. One student, Dee, had observed a "fuzzy edge" around the spots of light created by their flashlights and tubes. Dee joked that she "wasn't hallucinating" when other students finally saw the same feature. They discussed whether or not their observation reflected something physical, considering whether or not it was an artifact of how they initially wrapped their paper. They decided that they needed to develop a new model to explain this puzzling observation, and they eventually developed an experiment to test their model.

\section{E. Summary of examples}

Within each of these episodes, a student works to articulate what it is that they do not understand. 
- Jared and Ben worked to explain the inconsistency between the idea that water molecules "get packed together" to become ice and the phenomenon of water expanding when it freezes. Another student, Jack, rearticulated the question to ask how water molecules, as they pack together, end up expanding.

- Michael describes how he is "unhappy" with his answer to a homework question, but cannot pinpoint a problem with his argument. Later on, Connor highlighted the discrepancy between the results of at-home experiments and the answer given in class.

- Pat struggled to articulate what had her uneasy about the professor's solution to a homework problem concerning someone walking up an escalator. She found it helpful to consider a person jumping up and down on a single step, which isolated what was troubling her: the varying strength of interaction between the escalator and the person.

- Dee, Jordan, and their classmates identified a phenomenon, the fuzzy edge, and worked to articulate the problem it presented for their understanding. This involved their distinguishing what about the fuzzy edge was of fundamental concern given their model and what was a less interesting artifact of their setup. The first case began with a student's finding an inconsistency between a model and observation, the second with a students' unhappiness with an answer they had constructed, the third with a student's dissatisfaction over an explanation, and the fourth with students' noticing a strange phenomenon. Each involved more than simply "asking a question." Rather, a significant portion of the activity was in constructing a question and identifying, articulating, and motivating a problem.

\section{CONCLUSION AND IMPLICATIONS}

Einstein and Infeld wrote of the importance of "the formulation of a problem," how it "requires creative imagination and marks real advance in science" (Ref. [42], p. 95). It is difficult work to specify the "shape of the gap" [2] in one's understanding, as Henle put it, or in the community's. Problems are thus achievements, often the products of sustained effort. We gave several seminal examples from the professional literature [5-7].

Our first purpose in this article has been to call explicit attention to problematizing as an aspect of scientific inquiry, the intellectual activity of identifying, articulating, and motivating a gap or inconsistency of understanding. The importance and challenge of that activity is mostly missing from curricula and standards that depict science as beginning with questions [1,9].

Our second purpose has been to show the beginnings of problematizing in student thinking. We gave three examples from a sample we collected as part of a larger study of students' engagement in science. They included moments of students trying to determine what the gap or inconsistency was in their understanding, as well as moments of students, convinced themselves, trying to convince their classmates that something was missing or amiss.

With the methods of this study, we cannot make any claims about frequency or conditions. However, that we found students' problematizing in most of the cases we had vetted only as exemplars of students' "doing science" motivates a tentative conclusion: Problematizing, we suggest, is a common part of student inquiry. There are important implications for research and instruction.

\section{A. Implications for research}

First, we are proposing significantly more research to study student problematizing, to complement the extensive work on problem solving, and to guide new thinking about curriculum and instruction. When, how, and in what ways do students spend time and effort to formulate productive questions, such as to examine and articulate "what is it that's troubling me?" or "what precisely is the question we should be trying to answer?"

There have been similar calls in prior work. Kilpatrick called specifically for greater attention to problem formulating in math curriculum and education research, arguing for its central importance in the discipline [43]. There has been significant work in problem posing more recently, but this work tends to focus on students' posing problems that are similar in nature to homework exercises students might be expected to solve $[44,45]$, rather than problems grounded in disciplinary uncertainties.

Students' problematizing is an implicit component of their seeking coherence, in the recent account of Sikorski and co-workers $[46,47]$. She emphasized that "what students see as consistent may look inconsistent to educators, and vice versa" (Ref. [46], p. 150), and this implies the need to support students in formulating and pursuing their own questions.

There has been far more explicit attention to "problem scoping" in engineering education, as a core disciplinary aspect of engineering design [48]. Design studies research emphasizes the coevolution of problems and solutions [49,50]. For example, in Ref [50], Maher and Poon describe the design process as an iterative coevolution of the "design/ solution space" and the "problem space." As an engineer works to develop a design or solution, they discover more constraints and the problem they are attempting to solve evolves. Accounts of students' problem scoping show similar dynamics in how students identify and balance problem criteria as they develop their solutions [51]. There is similar iteration and coevolution in the cases we presented of students constructing and revising questions in the course of problem solving.

Recent accounts consider the role of students' "framing" what they are doing in engineering design to understand how they engage in disciplinary activities [52,53]. For 
example, in Ref. [53], Wendell studied how her students framed their work as they designed for a fictional client, navigating among different aspects of the engineering design process. She considered in particular why they spent little time scoping the problem, moving too quickly to generating ideas for solutions.

Further research should study dynamics in science, where there are likely to be complex, nested framings of problem forming and problem solving. In related work emerging from the larger project, we are studying students' experiences of uncertainty and not understanding, which a number of authors have recently highlighted as pervasive in science [24,54-56]. In particular, we are exploring how students' tolerance or even enjoyment of uncertainty [57,58], and their comfort positioning themselves as not understanding within a discussion, may help spark or sustain their engagement in doing science [36].

Finally, we see an implication of this work for research on argumentation. In general, that work has been concerned with "debate and argumentation around competing theories, methodologies and aims" (Ref. [59], p. 40). The examples above, from both scientists and students, suggests expanding the notion to include argumentation around the existence of gaps and inconsistencies. In other words, scientists and students may engage in argumentation over whether there is something they do not understand and, therefore, if they have a problem. In this it may be useful to draw upon the characterization of Berland and Reiser of the three practices of students' scientific argumentation: (1) sense making, (2) articulating, and (3) persuading [60]. When students problematize in our cases, we see them sense making around phenomena in the same sense as the work of Berland and Reiser. In addition to articulating and persuading others of models or theories, we see students articulating and persuading others of problems or uncertainties.

\section{B. Implications for instruction}

In broad terms, this work supports and refines arguments developed elsewhere. All of the episodes we presented took place in contexts that afforded students epistemic agency $[61,62]$, including with respect to assessing the quality of their own understandings, formulating questions, and deciding where to focus their attention [57,58,63,64]. The instructors were all responsive to student thinking, noticing and foregrounding student thinking, helping to clarify and focus the classes' attention [65].

In fact, looking across the four cases we have considered here (including the Supplemental Material [31]), two took place in courses designed with little or no predetermined agenda to cover material in the canon. Freezing water was part of a project focused on responsive teaching in elementary school science, with only minimal need to study topics in and around the water cycle $[38,66]$. The fuzzy edge of a light spot was part of a course specifically focus on scientific inquiry [28-30]. For contexts such as these, this work may support student and teacher awareness regarding aspects of what they are already doing.

The other two episodes took place within a course that included significant objectives of canonical ideas in Newtonian mechanics. In that context, the discussion of the block and cylinder question posed challenges for the instructor: encouraging the productive discussion stood at odds with the need to move forward through the content of the course. As well, Pat's and Connor's accomplishments in formulating productive new questions, in the escalator and block and cylinder cases, would be difficult to support in a systematic way across the course's enrollment. Even in that course, reformed to focus on student epistemologies, the vast majority of problems are provided by the instructor or curriculum materials.

In more specific terms, the implications of this work for instruction are for greater emphasis on student problematizing. For most instructional contexts, this may be difficult. How, for example, might we incorporate students' authoring problems into large-lecture courses? One approach is to incorporate student problematizing explicitly into interactive lectures and, as in the esclator episode, discussion sections. We have experimented with assigning students to compose problems, but it presses significantly on instructors' time in assessment. We have also included openresponse exam questions that afford problematizing, with possibilities of credit for students who successfully articulate problems. An example is given in the Supplemental Material [31]. But we would like to incorporate more, and this is a place for pedagogical innovation. Perhaps calibrated peer review tools [67-69] can provide a practical way to implement such assignments in large classes.

On a smaller scale, this work could inform day-to-day interactions with students, in the recognition of problematizing as an aspect of learning and doing science, regardless of course structure. Students often need to work-and they need to understand that they need to work-to find "the shape of the gap" [2] in their understanding and to investigate their confusion rather than try to avoid it or move too quickly to resolve it.

Instructors may be able help in small ways. They can display their own uncertainties and model how they manage them and how they feel about them as opportunities for pleasurable activity, rather than as embarrassments to avoid. A lecturer could shift from asking "are there any questions?" to "is anyone uneasy about anything?" offering opportunities for students to work with each other to formulate questions. Instructors can respond to students' confusion in similar ways, as opportunities, helping students to investigate their confusion and try to express it, to treat confusion as a positive sign of productivity: "Oh, that's great, you must be onto something useful. Can you articulate what's bothering you?"

In other words, instructors can help students learn to frame trying to articulate confusion as a part of what they 
do, as learners. For example, in Refs. [57,58] Radoff et al. present a case study of an introductory physics student who learned to frame confusion as intellectually enticing, an opportunity for inquiry, and the possibility of new insight and discovery. Radoff et al. describe this particular reorientation as transformative for that student in her experience of a course in introductory physics, and in her later pursuit of a career in research.

Experiences of uncertainty and confusion pervade learning science, and for students who think these experiences reflect something wrong about them as learners, thinking, for example, that "good students" or "smart students" do not feel confused in these ways, or that they know just what questions to ask, can be debilitating. Rather, students should learn that problematizing in this sense is part of healthy, effective, intelligent learning.

\section{ACKNOWLEDGMENTS}

This work was made possible by the efforts of our entire team, particularly Jennifer Radoff, Lama Jaber, and Leslie Atkins Elliott. This research is funded by the Gordon and Betty Moore Foundation through Grant No. GBMF3475 to D. Hammer, Tufts University. Some case studies, including "freezing water" are drawn from the Responsive Teaching in Science project, funded by National Science Foundation Grant No. 0732233.
[1] National Research Council, A Framework for K-12 Science Education: Practices, Crosscutting Concepts, and Core Ideas (National Academies Press, Washington, DC, 2012).

[2] M. Henle, in 1879 and All That: Essays in the Theory and History of Psychology, edited by M. Henle (Columbia University Press, New York, 1986), Chap. 14, pp. 172-189.

[3] M. Polanyi, Personal Knowledge: Towards a Post-Critical Philosophy (University of Chicago Press, Chicago, 1962).

[4] S. Bromberger, On What We Know We Don't Know: Explanation, Theory, Linguistics, and How Questions Shape Them (University of Chicago Press, Chicago, 1992).

[5] A. Einstein, B. Podolsky, and N. Rosen, Phys. Rev. 47, 777 (1935).

[6] A. H. Guth, Inflationary universe: A possible solution to the horizon and flatness problems, Phys. Rev. D 23, 347 (1981).

[7] R. Brustein, Origin of the blackhole information paradox, Fortschr. Phys. 62, 255 (2014).

[8] A. Einstein, M. Born, and H. Born, The Born-Einstein Letters; Correspondence between Albert Einstein and Max and Hedwig Born from 1916 to 1955 (Walker, New York, 1971).

[9] NGSS Lead States, Next Generation Science Standards: For States, by States (National Academies Press, Washington, DC, 2013).

[10] M. Scardamalia and C. Bereiter, Text-based and knowledge based questioning by children, Cognit. Instr. 9, 177 (1992).

[11] C. Chin, D. E. Brown, and B. C. Bruce, Student-generated questions: A meaningful aspect of learning in science, Int. J. Sci. Educ. 24, 521 (2002).

[12] M. Watts, G. Gould, and S. Alsop, Questions of understanding: Categorising pupils' questions in science, Sch. Sci. Rev. 79, 57 (1997).

[13] C. Chin and L.-G. Chia, Problem-based learning: Using students' questions to drive knowledge construction, Sci. Educ. 88, 707 (2004).
[14] C. Chin and J. Osborne, Students' questions: A potential resource for teaching and learning science, Stud. Sci. Educ. 44, 1 (2008).

[15] C. Chin and J. Osborne, Students' questions and discursive interaction: Their impact on argumentation during collaborative group discussions in science, J. Res. Sci. Teach. 47, 883 (2010).

[16] C. Chin and J. Osborne, Supporting argumentation through students' questions: Case studies in science classrooms, J. Learn. Sci. 19, 230 (2010).

[17] C. Chin and G. Kayalvizhi, Posing problems for open investigations: What questions do pupils ask?, Res. Sci. Technol. Educ. 20, 269 (2002).

[18] E. H. van Zee, M. Iwasyk, A. Kurose, D. Simpson, and J. Wild, Student and teacher questioning during conversations about science, J. Res. Sci. Teach. 38, 159 (2001).

[19] C. A Chinn, L. A. Buckland, and A. Samarapungavan, Expanding the dimensions of epistemic cognition: Arguments from philosophy and psychology, Educ. Psychol. 46, 141 (2011).

[20] L. R. Herrenkohl and M. R. Guerra, Participant structures, scientific discourse, and student engagement in fourth grade, Cognit. Instr. 16, 431 (1998).

[21] H. Lee and Y. Cho, Factors affecting problem finding depending on degree of structure of problem situation, J. Educ. Res. 101, 113 (2007).

[22] H. A. Simon, The structure of ill structured problems, Artif. Intell. 4, 181 (1973).

[23] R. A. Engle and F. R. Conant, Guiding principles for fostering productive disciplinary engagement: Explaining an emergent argument in a community of learners classroom, Cognit. Instr. 20, 399 (2002).

[24] R. A. Engle, in Design Research on Learning and Thinking in Educational Settings: Enhancing Intellectual Growth and Functioning, edited by D. Y. Dai (Taylor and Francis, London, 2012), Chap. 7, pp. 161-200. 
[25] O. Zaslavsky, Seizing the opportunity to create uncertainty in learning mathematics, Educ. Stud. Math. 60, 297 (2005).

[26] The Dynamics of Learners' Engagement and Persistence in Science, http://studentsdoingscience.tufts.edu/.

[27] http://ase.tufts.edu/education/responsiveteachinginscience/.

[28] L. A. Elliott, K. Jaxon, and I. Salter, Composing Science: A Facilitators Guide to Writing in the Science Classroom (Teachers College Press, New York, 2016).

[29] I. Y. Salter and L. J. Atkins, What students say versus what they do regarding scientific inquiry, Sci. Educ. 98, 1 (2014).

[30] I. Salter and L. Atkins, Student-generated scientific inquiry for elementary education undergraduates: Course development, outcomes and implications, J. Sci. Teach. Educ. 24, 157 (2013).

[31] See Supplemental Material at http://link.aps.org/ supplemental/10.1103/PhysRevPhysEducRes.13.020107 for in-depth analyses of the "the work by an escalator" and "the fuzzy edge" cases.

[32] S. J. Derry, R. D. Pea, B. Barron, R. A. Engle, F. Erickson, R. Goldman, R. Hall, T. Koschmann, J. L. Lemke, M. G. Sherin et al., Conducting video research in the learning sciences: Guidance on selection, analysis, technology, and ethics, J. Learn. Sci. 19, 3 (2010).

[33] D. Tannen, Framing in Discourse (Oxford University Press on Demand, Oxford, UK, 1993).

[34] B. Jordan and A. Henderson, Interaction analysis: Foundations and practice, J. Learn. Sci. 4, 39 (1995).

[35] R. P. McDermott, K. Gospodinoff, and J. Aron, Criteria for an ethnographically adequate description of concerted activities and their contexts, Semiotica 24, 245 (1978).

[36] J. E. Watkins, D. Hammer, J. Radoff, L. Z. Jaber, and A. McLean Phillips, The position of not knowing as a spark for students scientific engagement (to be published).

[37] See http://studentsdoingscience.tufts.edu/case-studies/ freezing-water-bottle/more/ for full video.

[38] L.Z. Jaber and D. Hammer, Learning to feel like a scientist, Sci. Educ. 100, 189 (2016).

[39] E. F. Redish and D. Hammer, Reinventing college physics for biologists: Explicating an epistemological curriculum, Am. J. Phys. 77, 629 (2009).

[40] The full video of the case can be viewed at http:// studentsdoingscience.tufts.edu/case-studies/block-andcylinder/more/.

[41] H. G. Close, L. S. Gomez, and P. R. L. Heron, Student understanding of the application of Newton's second law to rotating rigid bodies, Am. J. Phys. 81, 458 (2013).

[42] A. Einstein and L. Infeld, The Evolution of Physics: The Growth of Ideas from Early Concepts to Relativity and Quanta, 1st ed. (Simon and Schuster, New York, 1938).

[43] J. Kilpatrick, in Cognitive Science and Mathematics Education, edited by A.H. Schoenfeld (Lawrence Erlbaum Associates, Inc., Hillsdale, NJ, 1985), Chap. 5, pp. 123-147.

[44] E. A. Silver, On mathematical problem posing, Learn. Math. 14, 19 (1994).

[45] F. M. Singer, N. Ellerton, and J. Cai, Problem-posing research in mathematics education: New questions and directions, Educ. Stud. Math. 83, 1 (2013).
[46] T.-R. J. Sikorski, Ph.D. thesis, University of Maryland, 2012.

[47] T. R. Sikorski and D. Hammer, in Learning in the Disciplines: Proceedings of the 2010 International Conference of the Learning Sciences, edited by K. Gomez, L. Lyons, and J. Radinsky (International Society of the Learning Sciences, Chicago, 2010), pp. 1032-1039.

[48] C. J. Atman, K. Yasuhara, R. S. Adams, T. J. Barker, J. Turns, and E. Rhone, Breadth in problem scoping: A comparison of Freshman and Senior engineering students, Int. J. Eng. Educ. 24, 234 (2008).

[49] K. Dorst and N. Cross, Creativity in the design process: Co-evolution of problem-solution, Design Studies 22, 425 (2001).

[50] M. L. Maher and J. Poon, Modeling design exploration as co-evolution, in Microcomputers in Civil Engineering (Blackwell Publishers, Cambridge MA, 1996), Vol. 11, pp. 195-209.

[51] J. Watkins, K. Spencer, and D. Hammer, Examining young students problem scoping in engineering design, J. Precoll. Eng. Educ. Res. 4, 5 (2014).

[52] M. E. McCormick and D. Hammer, Stable beginnings in engineering design, J. Precoll. Eng. Educ. Res. 6, 4 (2016).

[53] K. B. Wendell, Design practices of preservice elementary teachers in an integrated engineering and literature experience, J. Precoll. Eng. Educ. Res. 4, 4 (2014).

[54] L. K. Berland and B. J. Reiser, Classroom communities' adaptations of the practice of scientific argumentation, Sci. Educ. 95, 191 (2011).

[55] R. Lehrer and L. Schauble, in Handbook of Child Psychology, edited by K. A. Renninger and I. E. Siegel (Wiley, Hoboken, NJ, 2006).

[56] E. Manz, Understanding the codevelopment of modeling practice and ecological knowledge, Sci. Educ. 96, 1071 (2012).

[57] J. Radoff, L. Z. Jaber, and D. Hammer, in Proceedings of the Physics Education Research Conference (American Association of Physics Teachers, College Park, MD, 2016), pp. 260-263.

[58] J. Radoff, L. Z. Jaber, and D. Hammer, It's scary but it's also exciting: A case of meta-affective learning in science (to be published).

[59] R. A. Duschl and J. Osborne, Supporting and promoting argumentation discourse in science education, Stud. Sci. Educ. 38, 39 (2002).

[60] L. K. Berland and B. J. Reiser, Making sense of argumentation and explanation, Sci. Educ. 93, 26 (2009).

[61] M. Scardamalia, Can schools enter a knowledge society?, in Educational Technology and the Impact on Teaching and Learning, edited by M. Selinger and J. Wynn (Abingdon, RM, 2002), pp. 6-10

[62] C. I. Damşa, P. A. Kirschner, J. E. B. Andriessen, G. Erkens, and P. H. M. Sins, Shared epistemic agency: An empirical study of an emergent construct, J. Learn. Sci. 19, 143 (2010).

[63] J. E. Coffey, in Everyday Assessment in the Science Classroom, edited by J. M. Atkin and J. E. Coffey (National Science Teachers Association Press, Arlington, VA, 2003), pp. $75-88$. 
[64] X. Tang, J. E. Coffey, A. Elby, and D. M. Levin, The scientific method and scientific inquiry: Tensions in teaching and learning, Sci. Educ. 94, 29 (2010).

[65] A. D. Robertson, R. E. Scherr, and D. Hammer, Responsive Teaching in Science and Mathematics (Routledge, New York, 2015).

[66] J.E. Lineback, The redirection: An indicator of how teachers respond to student thinking. J. Learn. Sci. 24, 419 (2015).
[67] http://cpr.molsci.ucla.edu/Home.aspx.

[68] E. Price, F. Goldberg, S. Patterson, and P. Heft, Supporting scientific writing and evaluation in a conceptual physics course with calibrated peer review, AIP Conf. Proc. 1513, 318 (2013).

[69] E. Price, F. Goldberg, S. Robinson, and M. McKean, Validity of peer grading using Calibrated Peer Review in a guided-inquiry, conceptual physics course, Phys. Rev. Phys. Educ. Res. 12, 020145 (2016). 